\title{
Study on Anchor Cable instead of Single Hydraulic Prop Support in Advance Support of Deep Roadway
}

\author{
Wenpeng Su, ${ }^{1}$ Boyang Zheng, ${ }^{2}$ and Pengfei Jiang $\mathbb{C}^{2}$ \\ ${ }^{1}$ Publicity Department of the Working Committee of Qingdao, West Coast New Area of the Communist Party of China, \\ Qingdao 266000, China \\ ${ }^{2}$ College of Energy and Mining Engineering, Shandong Province (Shandong University of Science and Technology), \\ Qingdao 266590, China \\ Correspondence should be addressed to Pengfei Jiang; 17854251086@163.com
}

Received 14 December 2020; Revised 3 January 2021; Accepted 11 January 2021; Published 25 January 2021

Academic Editor: Hualei Zhang

Copyright (C) 2021 Wenpeng Su et al. This is an open access article distributed under the Creative Commons Attribution License, which permits unrestricted use, distribution, and reproduction in any medium, provided the original work is properly cited.

\begin{abstract}
In order to solve the problems of complicated advanced support process, high labor intensity, affecting the rapid advance of working face and the destruction of roof bolt (cable) by advance single hydraulic prop in ultra kilometer deep mine roadway, the deformation characteristics of roadway surrounding rock is analyzed. Taking the 27304 working face of Wanglou coal mine as the engineering background, numerical simulation, field monitoring, and theoretical calculation were used to analyze the deformation characteristics of roadway surrounding rock within the advanced influence range of 27304 working face. This paper puts forward the active advance support technology scheme, in which grouting anchor cable replaces the existing single hydraulic prop in the advance influence range of the working face in the ultra-kilometer deep mine, and observes and analyzes the deformation and failure characteristics of the surrounding rock of the working face advance roadway. The numerical simulation results show that in the advanced influence range of deep roadway, grouting anchor cable was used to replace the previous single hydraulic prop, and the vertical stress at both ends of the working face decreased by $15 \mathrm{MPa}$, with a decrease rate of $33.3 \%$; the displacement of roadway roof, floor, and two sides decreased by $10 \mathrm{~mm}, 55 \mathrm{~mm}$, and $20 \mathrm{~mm}$, with a decrease rate of $40 \%, 68.75 \%$, and $47.6 \%$, respectively. The field monitoring results show that the roof separation is obviously improved after using grouting anchor cable as the active advance support scheme. It solves the problem of safe and efficient production faced by the ultra-kilometer deep shaft in Wanglou coal mine and provides theoretical and technical support for unmanned double roadway advance support under the condition of safe and efficient mining.
\end{abstract}

\section{Introduction}

With the depletion of China's shallow coal resources, China's coal mines are extending to the depth at the mining speed of $8-12 \mathrm{~m}$ per year $[1,2]$. The mining of coal resources is gradually turning to the deep [3]. The engineering geology and hydrogeology conditions of roadway surrounding rock mass are becoming more and more complex, the physical and mechanical properties of deep rock mass change [4-6], the initial ground stress of the original rock is destroyed by engineering excavation disturbance, and the redistribution of ground stress leads to secondary stress field, which is the main reason for the occurrence of geological disasters such as roof caving and floor heave of surrounding rocks, and seriously threatens the safe and efficient production of mines
$[7,8]$. The high ground stress along with the deep buried face of deep roadway increases the requirement of support. The supporting area of single support roof is small, and the problems of roadway roof sinking and coal side moving increase easily occur, which is difficult to meet the safety production requirements of ultra-deep working face. According to statistics, the total length of roadway of new coal mines in China is up to $12000 \mathrm{~km}$ every year, among which, the bolt support rate has reached over $80 \%$, and that of state-owned coal mines is higher [9]. With the development of roadway support technology in coal mine, the proportion of bolt support will continue to increase $[10,11]$.

In view of the roadway active support, domestic and foreign scholars have carried out a lot of research. Du [12] proposed a multidimensional active control technology to 
control the stability of surrounding rock of roadway by using a new type of high-prestressed truss cable supporting roof and cable-channel steel truss supporting roadway side. Practical engineering shows that this technology can effectively improve the self-settling ability and antideformation ability of surrounding rock. Wang et al. [13] proposed the secondary support theory of high-stress composite active support system. Through numerical simulation and field observation, it was shown that the support system could effectively control the deformation and failure of surrounding rock. Zhao and $\mathrm{Ma}$ [14] adopted the methods of theoretical analysis, numerical calculation, and engineering practice, and by analyzing the reasons for failure of bolt-anchor cable support, they proposed a technical method to increase the extension of anchor cable. Du et al. [15] established the mechanical model of the composite active supporting system and obtained the critical condition of the pretension $Q y$ value when the truss anchor cable structure in the composite active supporting system reaches the balance of the system. Yao et al. [16] proposed the technical idea of adopting proactive support to replace proactive passive support in the area affected by the advance abutment pressure of the stoping face and realized the onetime active support in the full cycle of the service of the stoping roadway. Zheng and Wang [17] studied the mechanical adaptability of the bolt system accessories, and the results show that the tray arch structure has a significant impact on its bearing capacity. Cao et al. [18] established the two-phase failure mode of the bolt support system. The failure modes of cable bolting are discussed using a bond strength model as well as an iterative method. The interfacial shear stress model for ribbed bar is introduced, and a closed form solution is obtained using a triline stress strain relationship. Wu et al. [19] used numerical modeling to investigate the stress redistribution around roadway under different horizontal stress orientations. The influence of horizontal stress direction, pillar size between the roadways, and the excavation sequence of the roadways was examined. A reinforcing system which consists of high-strength rock bolts and cables was applied at the five roadways. Both the bolts and cables were installed with high pretension forces along the whole length of them. Field observation indicated that this reinforcing system was able to effectively restrain the deformation and failure of rock mass surrounding roadways. He et al. [20], through 2D finite element method (FEM), conducted numerical studies to investigate the arching effect and the importance of rock bolting. Results show that $\sigma \mathrm{m}$ could be used as a reliable indicator to assess the arching effect.

However, most of the above research studies focus on shallow buried roadways, while there are few related research studies on super-kilometer deep buried roadways. Based on the research background of 27304 working face roadway in Wanglou coal mine, aiming at the serious damage of roadway roof by high ground stress and the large investment of advanced support personnel, this paper adopts theoretical analysis, field measurement, and other means to study the application of grouting anchor cable instead of single hydraulic prop in the advanced roadway of coal mining face. The original advanced support system is optimized to ensure the support strength and further reduce the labor intensity and advance support cost.

\section{The Engineering Situation}

Wanglou coal mine 27304 working face is located in the north wing of seven mining area. Ground elevation is $+33.3 \mathrm{~m} \sim+34.3 \mathrm{~m}$. Working face elevation is $-1141 \mathrm{~m} \sim$ $-1029 \mathrm{~m}$. The depth of coal seam is $1105 \mathrm{~m}$, the length of working face advancing direction is $1500 \mathrm{~m}$, the width of working face is $120 \mathrm{~m}$, the width of roadway is $4.9 \mathrm{~m}$, the mining height is $4.5 \mathrm{~m}$, and the cutting depth is $0.8 \mathrm{~m}$. According to the actual situation exposed by the two lanes on the working face, there is no false roof on the working face roof, but the direct roof is siltstone. The roadway layout scheme of 27304 working face is shown in Figure 1, and the top and bottom plates of the coal seam are shown in Figure 2.

\section{Design of Active Support Scheme}

According to the actual situation of Wanglou coal mine, the concrete construction scheme of anchor cable replacing single support in advance supporting section of roadway in working face is designed by theoretical calculation and field experience.

3.1. Original Support Scheme. Two groups of ZQL $2 \times 5000 /$ $21 / 40$ advanced supports and one group of ZT14000/19/40 end frame combined with single pillar shed support were used for the advance support of the working face. The shed was supported by $3.5 \mathrm{~m}-4.0 \mathrm{~m}$ " $\pi$ " beam combined with single hydraulic pillar, one beam with three pillars, shed spacing of $1.0 \mathrm{~m}$, middle pillar which is $2.5 \mathrm{~m}$ from the upper pillar, and middle pillar which is $1.0 \mathrm{~m}$ from the lower pillar.

Three groups of ZQL2 $\times 5000 / 21 / 40$ advance supports, single hydraulic prop, and hinged top beam support are used for the advance support of the lower channel of the working face, and single row prop support is used with the column spacing of $1.0 \mathrm{~m}$.

3.2. Roof Bolt Support Strength. The bolts on the roof were made of $\Phi 22 \times 2500 \mathrm{~mm}$ resin bolts with 7 bolts in each row, and the row spacing between bolts was $800 \times 800 \mathrm{~mm}$. Anchor is fastened with rubber washer and standard nut.

The breaking load of roof bolt is

$$
F_{1}=95 \mathrm{kN}
$$

The support density of roof bolt is

$$
p_{1}=\frac{7}{a_{1} \times a},
$$

where $p_{1}$ is roof bolt support density; $a_{1}$ is the row spacing of roof bolts, $a_{1}=800 \mathrm{~mm}$; and $a$ is the width of working face roadway, $a=4900 \mathrm{~mm}$. 


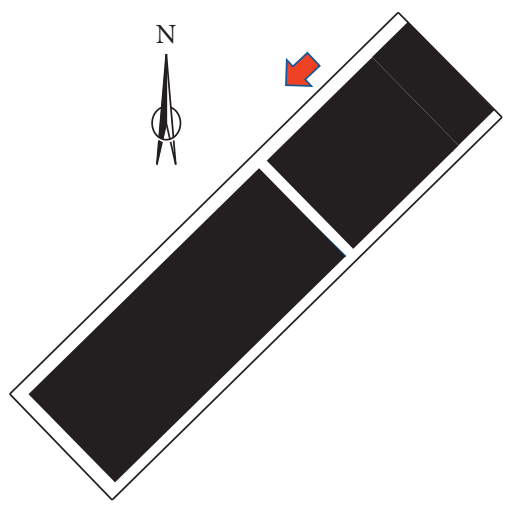

Figure 1: Roadway layout of 27304 working face.

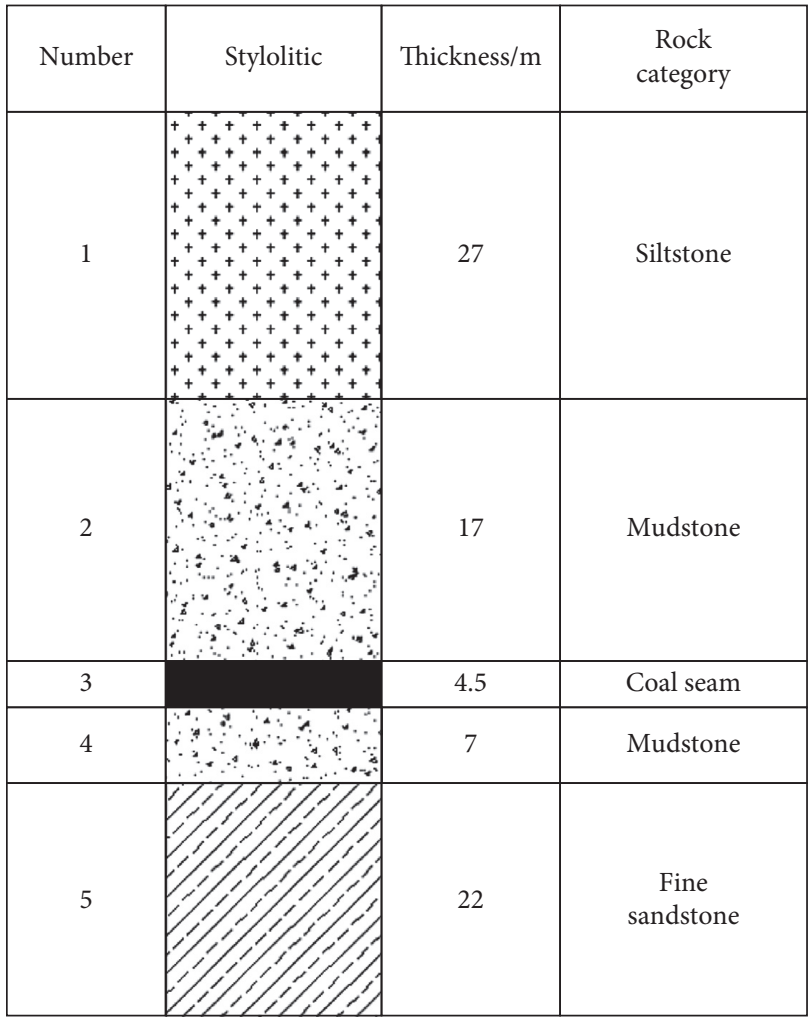

FIGURE 2: Roof and floor of coal sea.

$$
p_{1}=\frac{7}{a_{1} \times a}=\frac{1.79}{\mathrm{~m}^{2}}
$$

The support strength of roof bolt is

$$
W_{1}=F_{1} \times p_{1} .
$$

Get $W_{1}=0.170 \mathrm{MPa}$.

Then, the supporting force of roof bolt is

$$
Q_{g}=P_{1} \times a \times a_{1} .
$$

3.3. The Supporting Strength of Roof Anchor Cable. Three anchor cables were arranged to cooperate with anchor cable
TABLE 1: Relationship between number of anchor cables and row spacing.

\begin{tabular}{lcccccc}
\hline$a_{s}(\mathrm{~mm})$ & 800 & 900 & 1000 & 1200 & 1400 & 1600 \\
\hline$n$ & 2.56 & 2.88 & 3.2 & 3.84 & 4.48 & 5.12 \\
$N /$ root (recommended) & 3 & 3 & 4 & 4 & 5 & 6
\end{tabular}

tray to strengthen the support of roadway roof. The anchor cables were made of low relaxation steel strands of $\Phi$ $22 \times 8000 \mathrm{~mm}$, and the row spacing was $1600 \times 1600 \mathrm{~mm}$.

The breaking load of roof anchor cable is

$$
F_{2}=583 \mathrm{kN} \text {. }
$$

Roof anchor cable support density is

$$
p_{2}=\frac{3}{a_{2} \times a}
$$

where $p_{2}$ is roof anchor cable support density; $a_{2}$ is top plate cable row distance, $a_{2}=1600 \mathrm{~mm}$; and $a$ is the width of working face roadway.

We can solve

$$
p_{2}=\frac{3}{a_{2} \times a}=\frac{0.38}{\mathrm{~m}^{2}} .
$$

Roof bolting strength is

$$
W_{2}=F_{2} \times p_{2} .
$$

Get $W_{2}=0.223 \mathrm{MPa}$.

3.4. Checking the Original Support Strength during Tunneling. Through the above calculation, it can be known that the roof bolt and anchor cable arranged during tunneling can provide support strength as follows:

$$
\begin{aligned}
& W_{1}=0.170 \mathrm{MPa}, \\
& W_{2}=0.233 \mathrm{MPa} .
\end{aligned}
$$

Therefore, it can be concluded that the support strength provided by the support during the excavation of 27304 roadway is $0.393 \mathrm{MPa}$, which cannot reach the reasonable support strength of advanced support.

3.5. Reinforcement Parameters of Anchor Cable instead of Single Pillar in Advance Support during Stoping. According to the width of the roadway which is $4900 \mathrm{~mm}$, it is concluded that the supporting strength to be reinforced is $0.382 \mathrm{MPa}$.

The specification of anchor cable was $\Phi 22.0 \times 8000 \mathrm{~mm}$. The leading anchor cable tension load is $F_{s}=583 \mathrm{kN}$. The relationship between the number of anchor cables and row spacing is as follows:

$$
\begin{aligned}
n & =p_{s} \times a_{s} \times a, \\
p_{S} & =\frac{P_{S}}{F_{S}},
\end{aligned}
$$

where $n$ is the number of anchor cable roots; $P_{s}$ is the support strength to be provided; $P_{s}$ is the support density of 
advance anchor cable; $a_{s}$ is the advance anchor cable row distance; and $a$ is the width of working face roadway, $a=4900 \mathrm{~mm}$.

The relationship between the number of anchor cables and the row spacing can be obtained as shown in Table 1.

The relationship between the number of anchor cables to be increased and the row spacing of anchor cables was obtained. According to the specific geological conditions of Wanglou coal mine and the support layout during excavation, the row spacing can be $900 \mathrm{~mm}$, each row can be added with three $\Phi 22.0 \times 8000 \mathrm{~mm}$ anchor cables, and the roof can be supported with W-type steel belt, with the row spacing of $2400 \times 900 \mathrm{~mm}$. Combined with the actual site support, the row spacing between reinforcement cables can be set at $2400 \times 800 \mathrm{~mm}$. According to the calculation, the specific layout is as follows.

3.5.1. Upper Roadway of Working Face. The design net width and height of 27304 upper roadway are $4.9 \mathrm{~m}$ and $3.7 \mathrm{~m}$, respectively, which was constructed along the roof of coal seam. During the excavation, bolt mesh or anchor cable were used for roadway support. The bolts on the roadway roof were made of $\Phi 22 \times 2500 \mathrm{~mm}$ resin bolts with row spacing of $800 \times 800 \mathrm{~mm}$. The side part adopts $\Phi 22 \times 2500 \mathrm{~mm}$ righthanded full thread anchor rod, and the row spacing between anchor rods was $900 \times 800 \mathrm{~mm}$. Three anchor cables were arranged in each row of the roadway roof to cooperate with the anchor cable tray to strengthen the support. The anchor cables were made of low relaxation steel strands with a spacing of $1.6 \times 1.6 \mathrm{~m}$. The specific layout is shown in Figure 3 .

3.5.2. Lower Roadway of Working Face. The width and height of the Lower roadway of 27304 are $4.3 \mathrm{~m}$ and $3.7 \mathrm{~m}$, respectively, and the construction is carried out along the roof of coal seam. The roof and side of roadway are provided with $\Phi 20 \times 2600 \mathrm{~mm}$ high-strength pretension bolt, the row spacing of top bolt is $800 \times 800 \mathrm{~mm}$, and the row spacing of side bolt is $1000 \times 800 \mathrm{~mm}$. The low relaxation steel strand of $\Phi 22 \times 8000 \mathrm{~mm}$ is used as the anchor cable. Three anchor cables were arranged in each row, and the row spacing between anchor cables was $1600 \times 1600 \mathrm{~mm}$, which was arranged in the middle of two adjacent rows of bolts.

\section{Numerical Simulation Analysis}

Based on the geological conditions of 27304 working face of Wanglou coal mine, combined with the anchor cable support scheme of advance support section and the single support scheme, FLAC ${ }^{3 \mathrm{D}}$ finite element numerical simulation software was used to carry out a comparative analysis on the modeling of the two support types. The influence range of stress after roadway excavation is about $3 \sim 5$ times the width of roadway. Based on the actual production of coal mine, the model size is finally selected: $X \times Y \times Z=180 \mathrm{~m} \times 120 \mathrm{~m} \times 100 \mathrm{~m}$. In order to reduce the error caused by the grid division, the length-width ratio of the grid should not be greater than 5 . For the key research area, the grid can be densified. The unit size far from the roadway area is about $1 \mathrm{~m}$, and the size close to the roadway

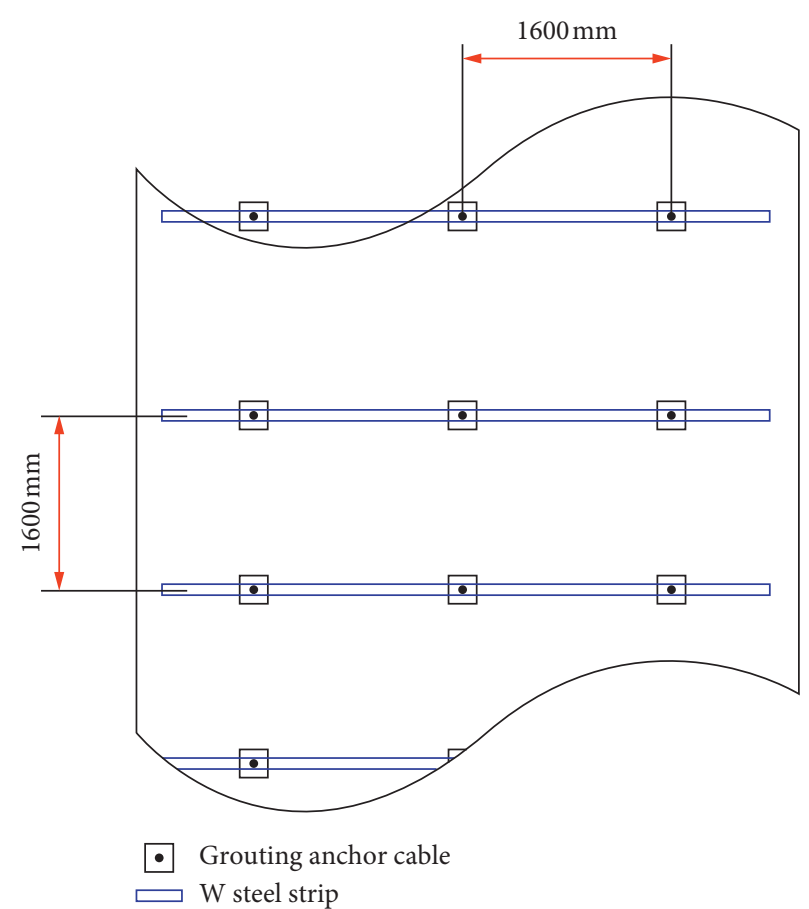

FIGURE 3: Schematic diagram of advanced support scheme design.

area and the roadway excavation area is $0.5 \mathrm{~m}$. For the key research area, the grid can be densified, and the whole model is a cube. A uniform load of $26.5 \mathrm{MPa}$ was applied to the roof of the model to simulate the pressure of rock strata along the negative side of $X$-axis; horizontal stress with a lateral pressure coefficient of 0.95 was applied around the model to simulate the horizontal stress. The bottom of the model was restrained to move in vertical direction, and the profile was restrained to move in horizontal direction. The initial displacement in each direction is 0 . The establishment of 3D model is shown in Figure 4. See Table 2 for the lithological physical and mechanical parameters of each rock mass in the model.

The Mohr-Coulomb model was used in the calculation, "Cable" structural element was used to simulate bolt support, and "Beam" structural element was used to simulate single hydraulic prop support. The cloud diagram of the maximum principal stress section of the model is shown in Figure 5 . The cloud diagram of vertical stress profile section is shown in Figure 6. By analyzing the cloud map of the simulation results, it can be found that the maximum principal stress on the end face of the anchor cable support is $30 \mathrm{MPa}$ and the stress is concentrated at the front of about $5 \mathrm{~m}$. The maximum principal stress on the end face of the monomer support reaches $45 \mathrm{MPa}$, and the stress concentration effect is increased. The normal stress of roof and floor is $97.5 \mathrm{MPa}$, and anchor cable support has a wider range of higher vertical stress distribution than monomer support.

The vertical displacement section of roadway surrounding rock is shown in Figure 7, and the section of horizontal displacement section is shown in Figure 8. It can be seen from the figure that the maximum displacement and settlement of the roof, the maximum displacement of floor heave, and the maximum displacement of side slope of single 


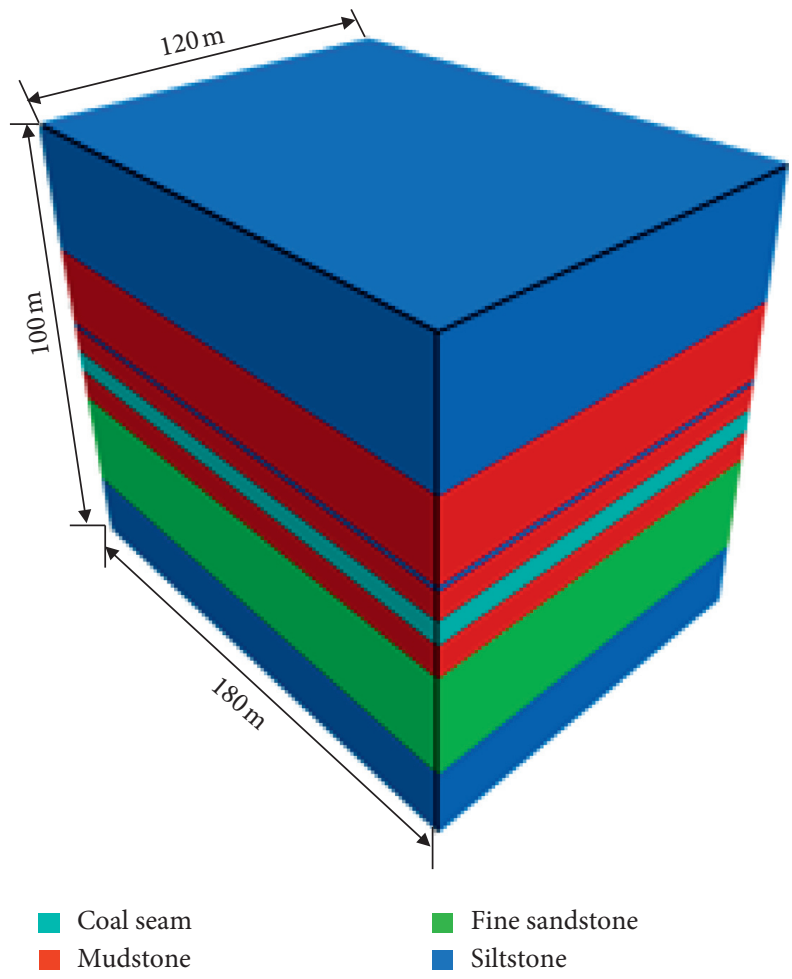

FIgURE 4: Numerical simulation model of mining roadway.

TABLE 2: The physical and mechanical parameters of surrounding rock.

\begin{tabular}{|c|c|c|c|c|c|c|}
\hline Rock category & Thickness (m) & Shear modulus (GPa) & Bulk modulus (GPa) & Cohesion $(\mathrm{MPa})$ & $\begin{array}{c}\text { Internal friction } \\
\text { angle }\left({ }^{\circ}\right)\end{array}$ & Tensile strength $(\mathrm{MPa})$ \\
\hline Siltite & 27 & 2.8 & 7.21 & 3.1 & 33 & 0.8 \\
\hline Mudstone & 17 & 4.13 & 2.41 & 1.78 & 25 & 0.7 \\
\hline Siltite & 1.3 & 2.5 & 6.8 & 2.8 & 31 & 0.8 \\
\hline Mudstone & 6.2 & 4.2 & 2.45 & 1.8 & 26 & 0.9 \\
\hline Coal seam & 4.5 & 1.35 & 2.13 & 1.21 & 30 & 0.12 \\
\hline Mudstone & 7 & 4.19 & 2.48 & 1.75 & 34 & 0.8 \\
\hline Fine sandstone & 22 & 2.8 & 7.21 & 3.1 & 33 & 0.8 \\
\hline Siltite & 15 & 3.05 & 7.25 & 3.5 & 32 & 0.8 \\
\hline
\end{tabular}

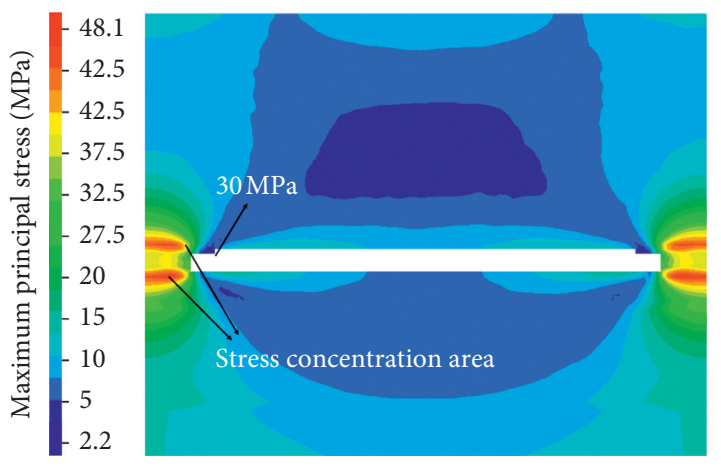

(a)

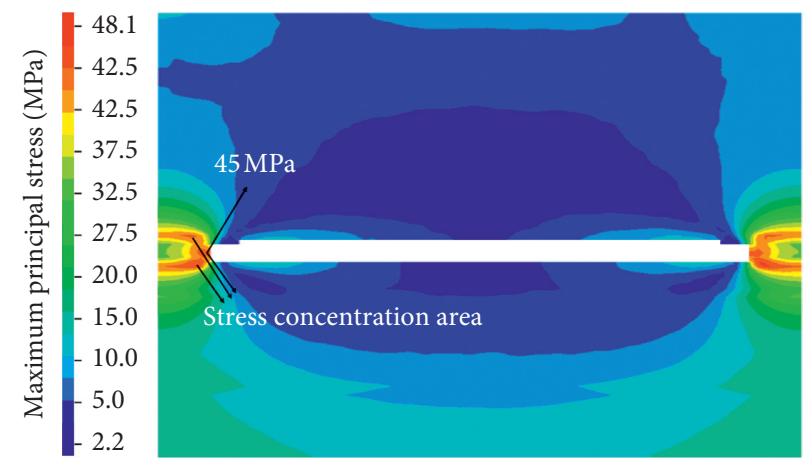

(b)

FIGURE 5: Section nephogram of maximum principal stress profile of different support types. (a) Single hydraulic prop support. (b) Anchor cable support. 


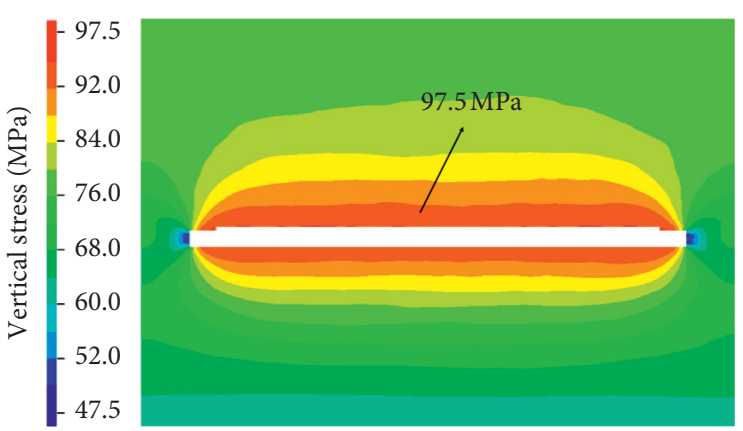

(a)

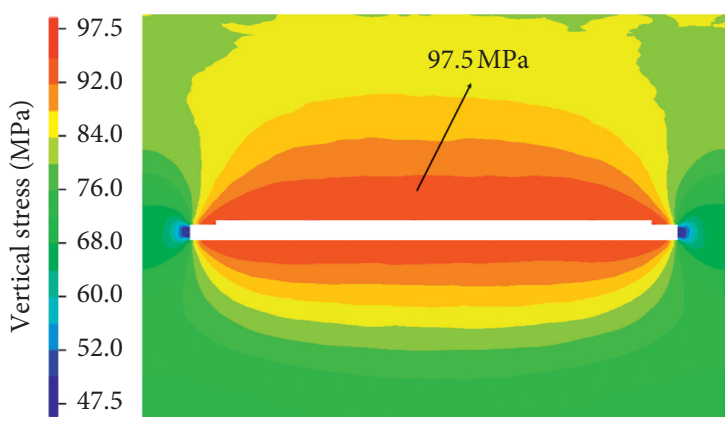

(b)

Figure 6: Vertical stress section nephogram of different support types. (a) Single hydraulic prop support. (b) Anchor cable support.
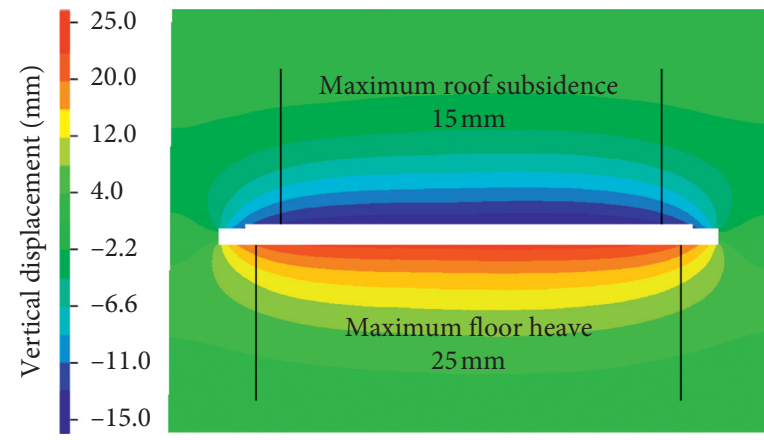

(a)

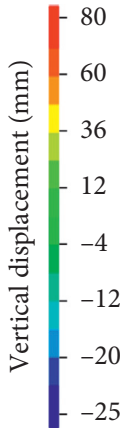

$-25$

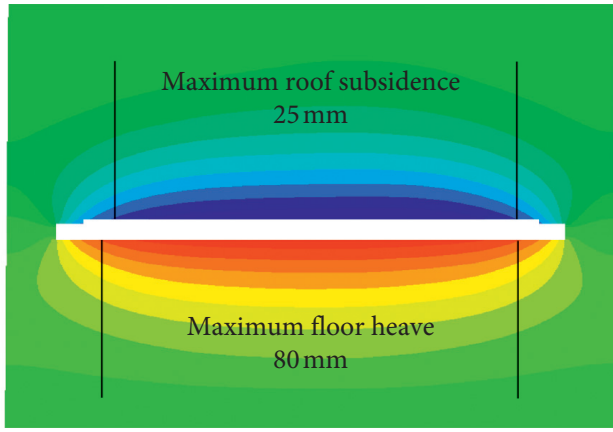

(b)

Figure 7: Cross section cloud map of vertical displacement profile. (a) Single hydraulic prop support. (b) Anchor cable support.

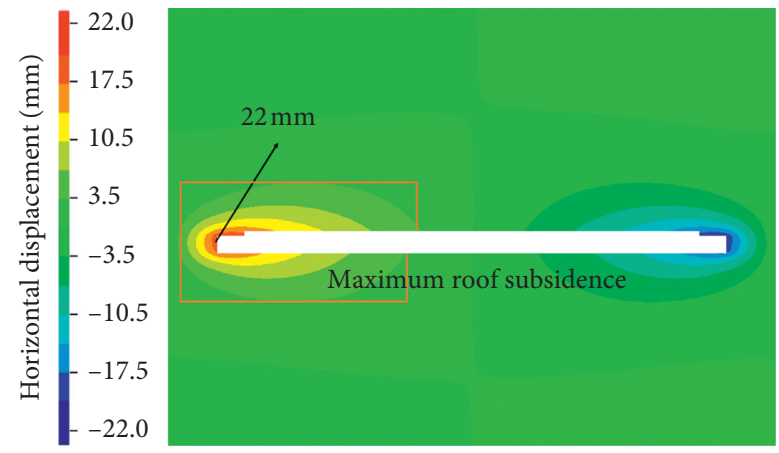

(a)

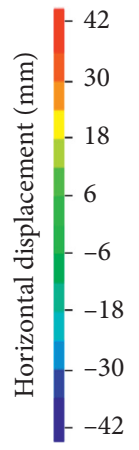

Figure 8: Horizontal displacement section nephogram. (a) Single hydraulic prop support. (b) Anchor cable support.

support roadway are $25 \mathrm{~mm}, 80 \mathrm{~mm}$, and $42 \mathrm{~mm}$, respectively; after using anchor cable support, the maximum displacements of roof, floor, and side slope are $15 \mathrm{~mm}$, $25 \mathrm{~mm}$, and $22 \mathrm{~mm}$, respectively, which are $40 \%, 68.75 \%$, and $47.6 \%$ lower than those of single support; especially, the displacement of floor heave decreased obviously. The displacement area of roof and floor with anchor cable support is smaller than that of single support. The higher horizontal displacement appears in the floor under the condition of single support, but not under the condition of anchor cable.
The schematic diagram of roadway deformation in surrounding rock is shown in Figure 9.

\section{Field Monitoring Plan and Data Analysis}

5.1. On-Site Monitoring Scheme. On-site monitoring is mainly divided into two parts: the roof separator is used to monitor the roof separation of material roadway and transportation roadway. A borehole peephole was arranged to monitor the development of loose circle. The specific monitoring scheme is arranged as follows: 


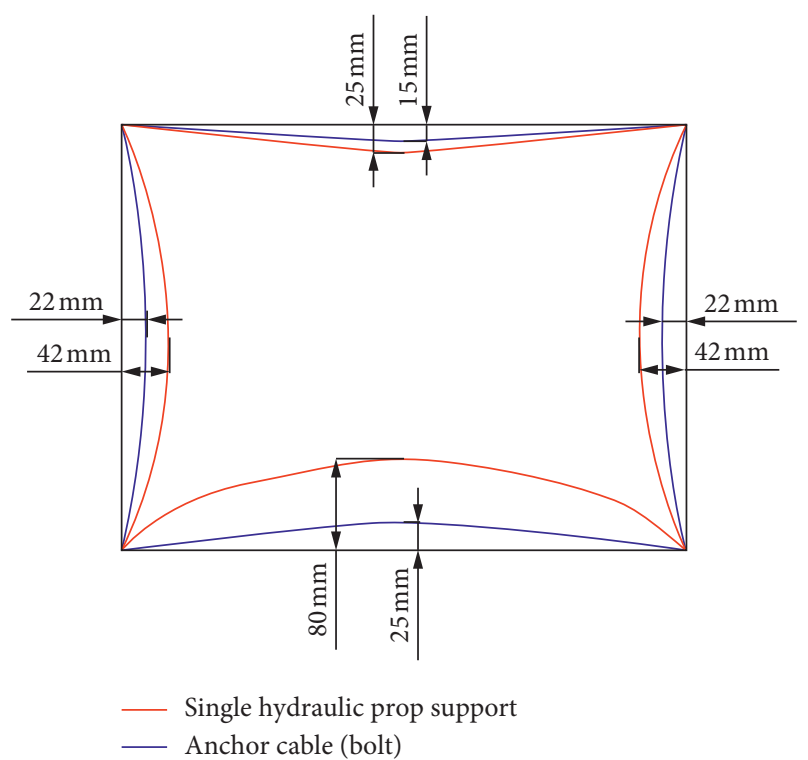

FIgURE 9: Displacement of model roadway.

(1) Layout scheme of roof separation instrument: in the material lane and transportation lane of 27304 working face, the first roof separation instrument is arranged at the top of each roadway $20 \mathrm{~m}$ away from the working face, and then one is arranged every $20 \mathrm{~m}$, with 5 in each roadway.

(2) Layout scheme of borehole peeping instrument: due to the same geological conditions of material lane and transportation roadway in 27304 working face, combined with the site construction situation and equipment placement, it was decided to arrange the peeping hole on the roof of material lane for construction and observation. In the material lane of " 3 lower" 2326 working face, the first group of peeping holes is arranged at $10 \mathrm{~m}$ away from the working face in the middle of the material lane after the stoppage of mining, and then a group of 5 is arranged every $10 \mathrm{~m}$. Each group of peeping boreholes (on the same section) includes two boreholes, which are, respectively, arranged at the roof and the roadway side waist line on one side of the coal body, and the drilling depth is $5.5 \mathrm{~m}$. The peeping boreholes are arranged at the track side of the haulage roadway of 27304 working face, $1 \mathrm{~m}$ away from the coal wall, and the working face is $10 \mathrm{~m}, 15 \mathrm{~m}, 20 \mathrm{~m}, 25 \mathrm{~m}, 30 \mathrm{~m}$, $40 \mathrm{~m}, 50 \mathrm{~m}, 60 \mathrm{~m}, 70 \mathrm{~m}$, and $80 \mathrm{~m}$ in advance, and the drilling depth is $9 \mathrm{~m}$, so as to carry out construction and observation. The location diagram of the measuring point is shown in Figure 10.

5.2. Data Analysis of Roof Separation Instrument. The same monitoring scheme is used to monitor the adjacent roadways which are similar to the roadways in 27304 working face under the same geological conditions. Through the analysis of monitoring data: when the shallow base point is $3.0 \mathrm{~m}$ and $1 \#$ measuring point adopts single support, there is a total

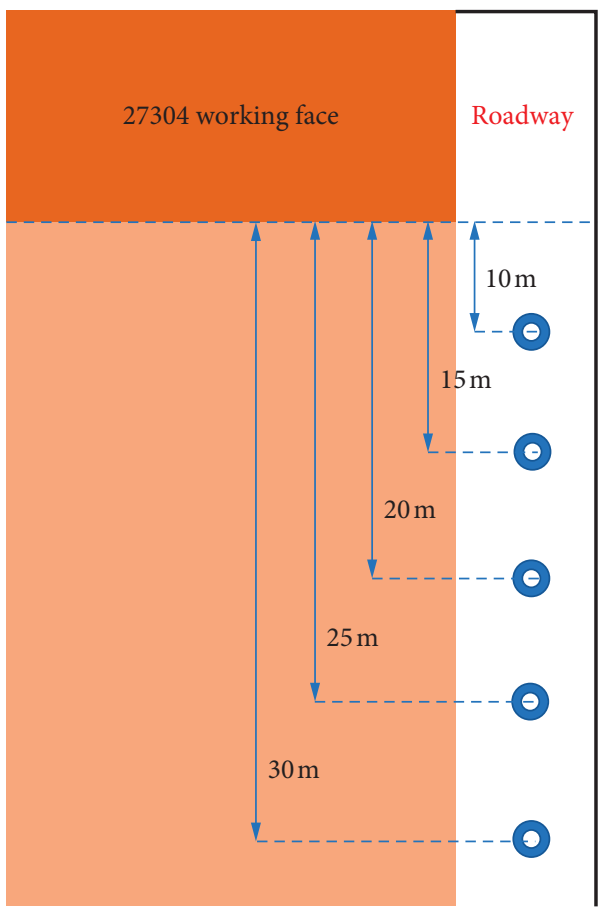

FIgURE 10: Schematic diagram of measuring point position.

displacement of $0.5 \mathrm{~mm}$ in 6 days before monitoring, compared with $0.5 \mathrm{~mm}$ displacement in 8 days before monitoring of bolt and cable support; within 20 days of monitoring, the displacement of single support roadway and anchor cable support roadway is $6.5 \mathrm{~mm}$, but it takes longer time for anchor cable support to reach the same displacement. During the monitoring period of 2\# measuring points, the cumulative displacement of single hydraulic prop support and anchor cable support was $1.8 \mathrm{~mm}$ and $0.5 \mathrm{~mm}$, respectively; during the monitoring period of $3 \#$ measuring points, their displacement was basically the same; during the 28 days of monitoring, the cumulative displacement of anchor cable support roadway of $4 \#$ measuring points was only $30.7 \%$ of that of single hydraulic prop support roadway. No displacement was detected at $5 \#$ measuring point during the monitoring period. The monitoring data of shallow base points are shown in Figure 11.

In the middle base point of $5.0 \mathrm{~m}$, the monomer support roadway and the anchor cable support roadway at $5 \#$ measuring point both eventually generated a $6.5 \mathrm{~mm}$ displacement, but the cumulative displacement curve "step" of the active support was relatively short, indicating that the anchor cable support was more sensitive to the change of surrounding rock stress and could give full play to its support ability rapidly. The cumulative displacement of $3 \#$ and $4 \#$ measuring points' anchor cable support is $1.5 \mathrm{~mm}$ and $1 \mathrm{~mm}$ less than that of single support, respectively. The decline was $22.2 \%$ and $30 \%$, respectively. During the monitoring period, no data were detected at 2\# and $5 \#$ measurement points. The monitoring data of midbase point are shown in Figure 12.

The deep base point is $9.0 \mathrm{~m}$, and the change trend and value of cumulative displacement of each measuring point are basically the same during the monitoring period, and the measuring points of $3 \#, 4 \#$, and $5 \#$ of monomer support and 


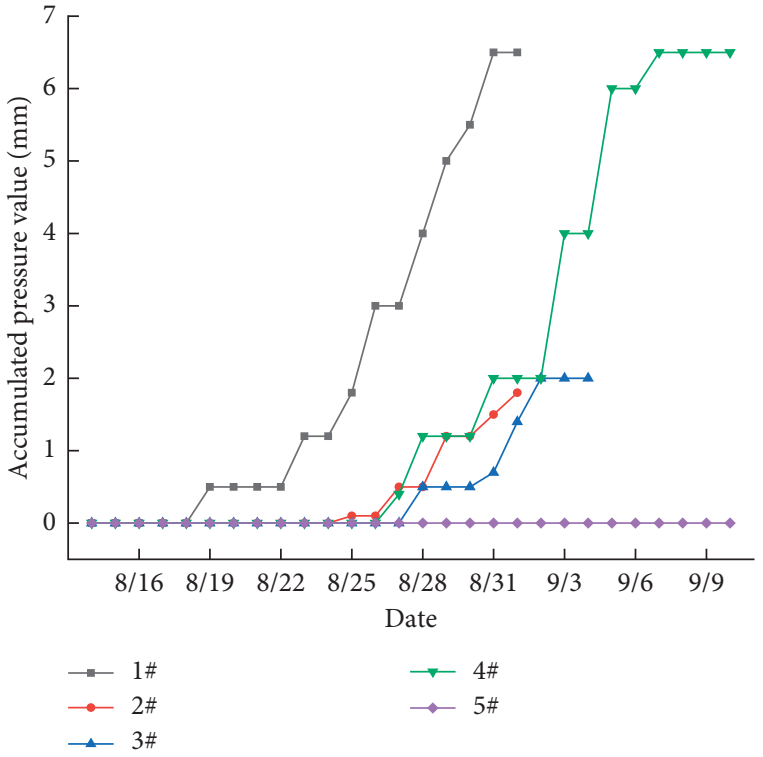

(a)

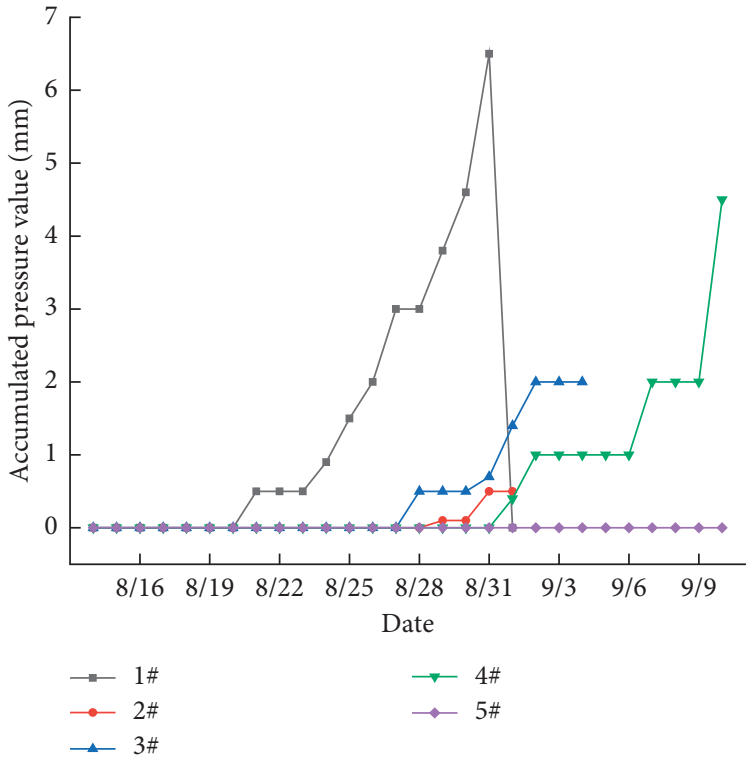

(b)

Figure 11: Monitoring data of shallow basis points. (a) Single hydraulic prop support. (b) Anchor cable support.

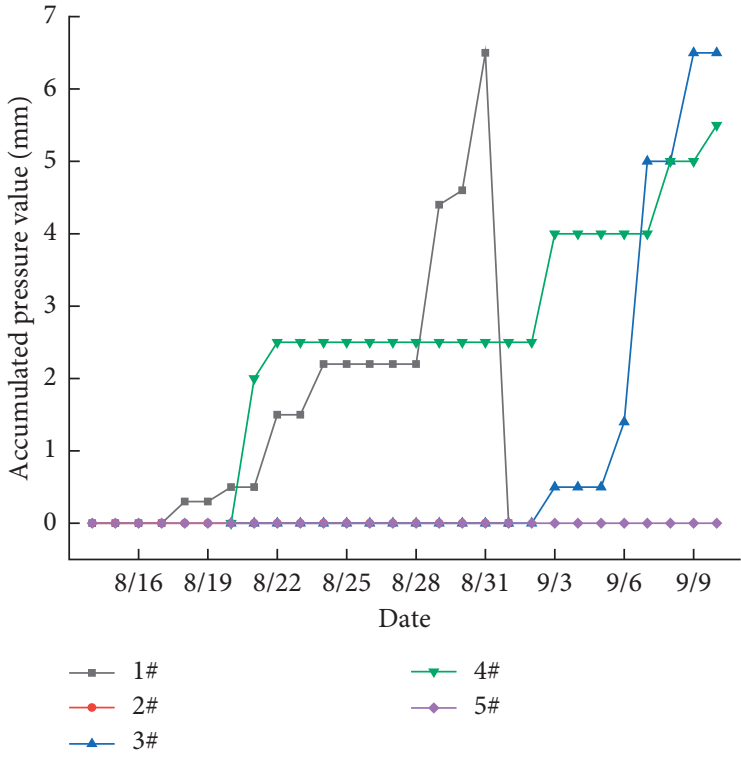

(a)

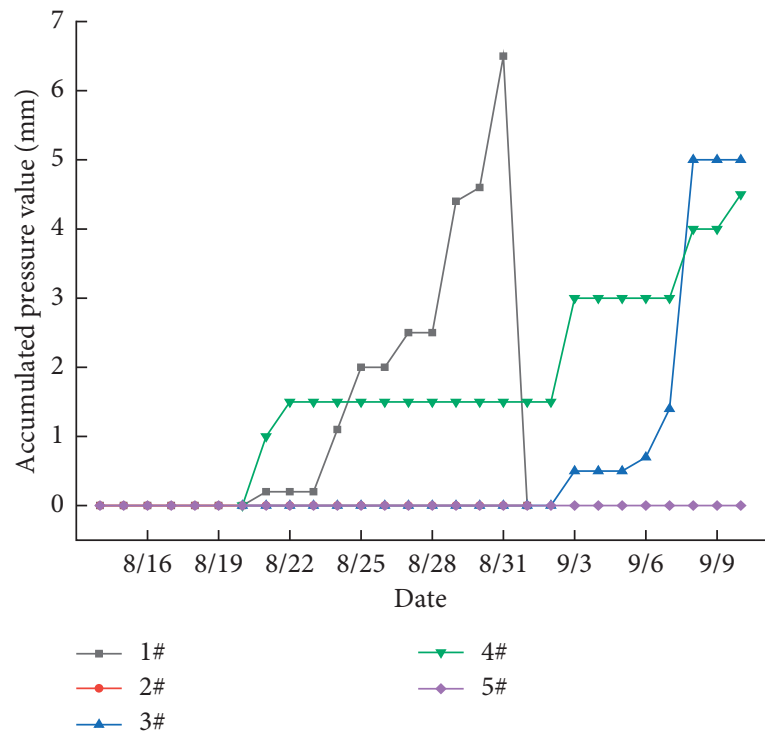

(b)

FIGURE 12: Medium base point monitoring data. (a) Single hydraulic prop support. (b) Anchor cable support.

anchor cable support are $1 \mathrm{~mm}, 1 \mathrm{~mm}$, and $0.5 \mathrm{~mm}$, respectively. No displacement was detected at $2 \#$ measuring point. It shows that the bolt (anchor cable) support is more effective than the single hydraulic prop support in controlling the displacement in the deep part of the roadway roof. The monitoring data of deep base point are shown in Figure 13.

Based on the comprehensive analysis of the roof separation data of each measuring point under the bolt (anchor cable) support scheme and single hydraulic prop support scheme, the shallow base point depth is $3 \mathrm{~m}$, the middle base point depth is $5 \mathrm{~m}$, and the deep base point depth is $9 \mathrm{~m}$. The time required for anchor cable support under the same displacement is shorter, and the cumulative displacement is also less than that of single support. Anchor cable support has the advantages of less roof separation, good integrity, and good roof support effect.

5.3. Data Analysis of Borehole Peepers. The station is $10 \mathrm{~m}$ away from the mining face, and the boreholes of 27304 haulage roadway are detected by RBIT- 30 borehole imager. In order to fully understand the information inside the borehole, through intercepting the development area of typical fractures in the borehole rock layer, the development and development characteristics of rock fractures in 


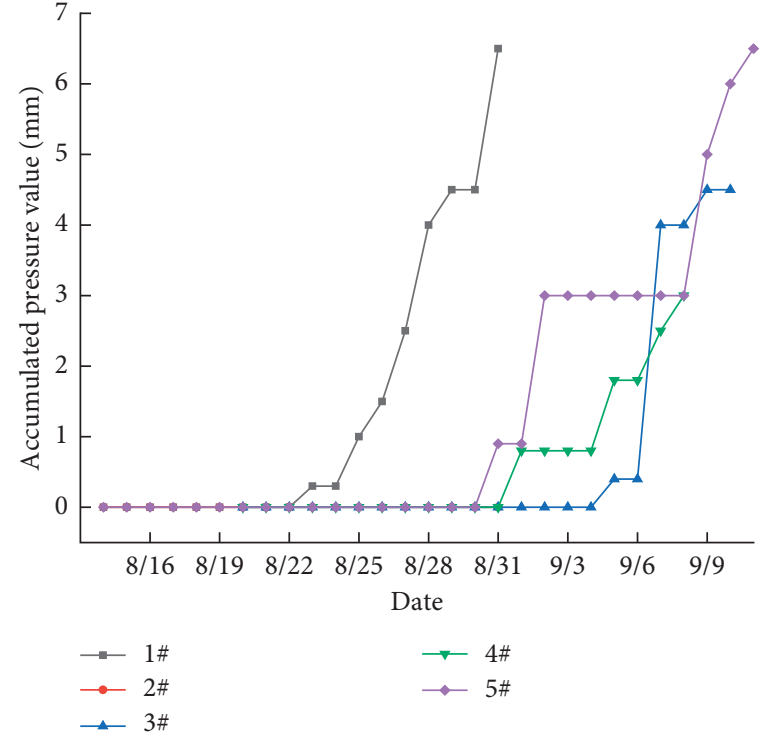

(a)

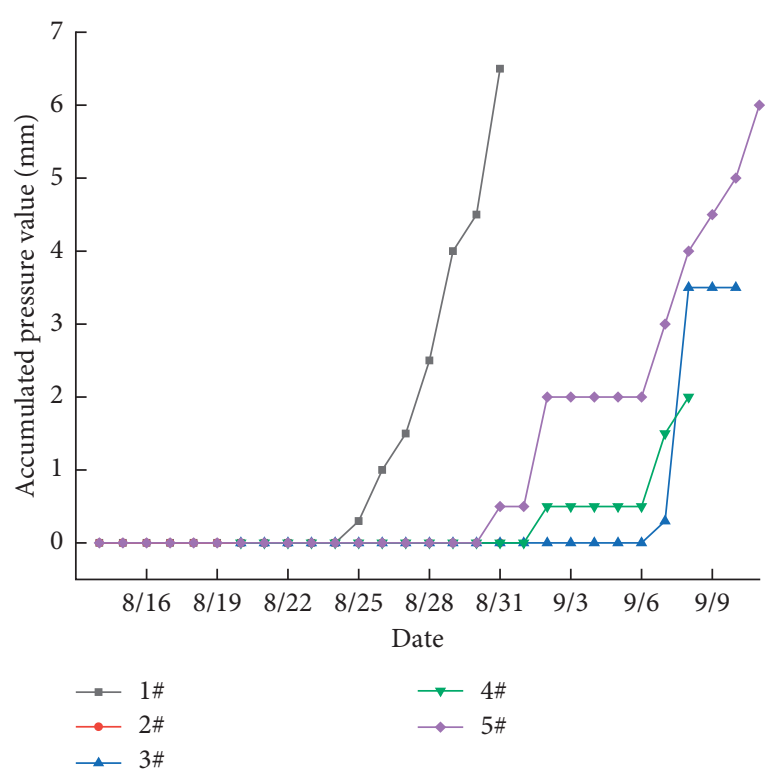

(b)

FIgURE 13: Monitoring data of deep base point. (a) Single hydraulic prop support. (b) Anchor cable support.

TABLE 3: Data of borehole peeping instrument.

\begin{tabular}{|c|c|c|c|}
\hline & Fracture development area $(\mathrm{m})$ & Separation zone $(\mathrm{m})$ & Crushing zone $(\mathrm{m})$ \\
\hline \multirow{2}{*}{$1 \#$} & $0.1-0.4$ & \multirow{2}{*}{$0.8-1.0$} & $0.5-0.8$ \\
\hline & $1.9-2.2$ & & $1.9-2.2$ \\
\hline $2 \#$ & $0.8-1.3$ & $0.4-0.8$ & $0.8-1.8$ \\
\hline \multirow[t]{2}{*}{$3 \#$} & \multirow{2}{*}{$0.1-1.0$} & \multirow{2}{*}{$1.5-1.6$} & $1.0-1.4$ \\
\hline & & & $2.7-3.0$ \\
\hline $4 \#$ & $0.1-0.5$ & $0.7-1.0$ & $1.5-2.2$ \\
\hline $5 \#$ & $0.1-1.0$ & $1.6-1.8$ & $0.9-1.1$ \\
\hline \multirow{2}{*}{$6 \#$} & \multirow[b]{2}{*}{$0.1-0.3$} & \multirow[b]{2}{*}{$0.7-1.2$} & $\begin{array}{l}1.4-2.1 \\
0.9-1.1\end{array}$ \\
\hline & & & $1.4-2.7$ \\
\hline 7\# & $\begin{array}{l}0.1-0.7 \\
0.9-1.4\end{array}$ & $1.7-1.9$ & $0.3-1.4$ \\
\hline $8 \#$ & $0.3-0.7$ & $2.7-3.0$ & $1.6-3.0$ \\
\hline \multirow{2}{*}{ 9\# } & \multirow{2}{*}{$0.1-0.3$} & \multirow{2}{*}{1} & $1.7-1.8$ \\
\hline & & & $2.6-3.0$ \\
\hline
\end{tabular}

boreholes are summarized and analyzed. This paper summarized and analyzed the development characteristics of rock fractures in each borehole and selected some representative screenshots (as shown in Figure 12) for explanation. According to the characteristics of roof structure and fracture development, the roof strata are divided into (1)fracture development area; (2) separation zone; and (3) crushing zone. The borehole data are shown 

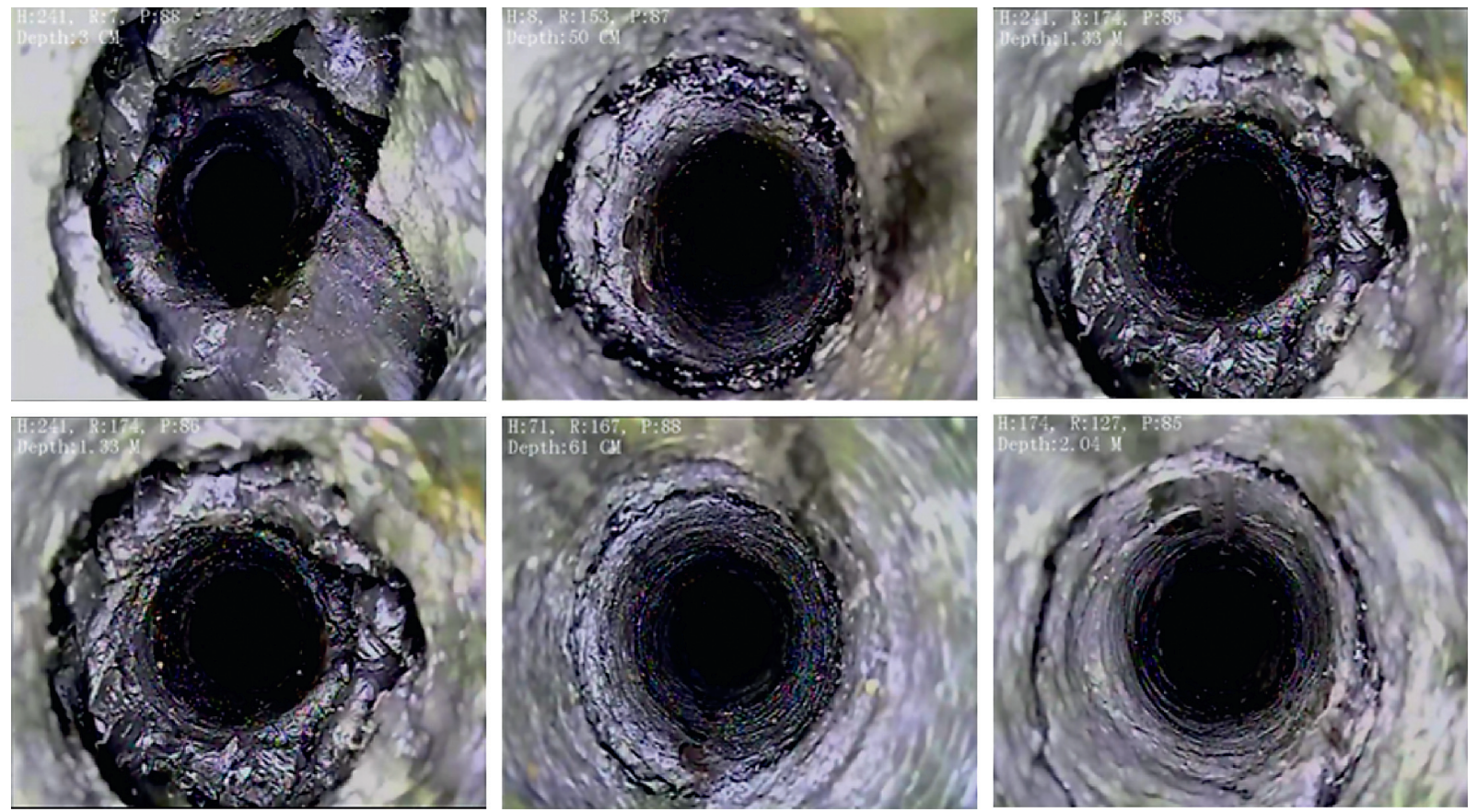

Figure 14: Distribution law of cracks in roof strata (3\# drill hole).

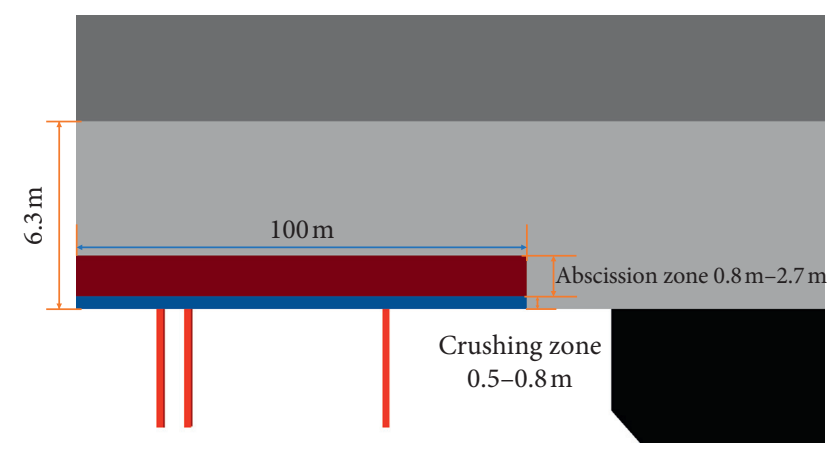

FIgURE 15: Distribution of roof separation zone.

in Table 3, and the distribution law of cracks in roof strata ( $3 \#$ drill hole ) is shown in Figure 14.

Combined with the analysis of roof separation instrument and borehole imaging results, the fracture area is roughly distributed in the range of $0.5 \mathrm{~m}-0.8 \mathrm{~m}$; the roof separation layer is generally distributed in the range of $0.8 \mathrm{~m}-2.7 \mathrm{~m}$. Through the data analysis of roof separation instrument, the maximum separation amount is $4.5 \mathrm{~mm}$, and the highest position is $2.7 \mathrm{~m}-3.0 \mathrm{~m}$. The distribution of roof separation zone is shown in Figure 15.

\section{Conclusion}

(1) By using FLAC ${ }^{3 \mathrm{D}}$ numerical simulation software, the stress distribution of the roadway supported by single hydraulic prop and the roadway supported by grouting anchor cable is compared and analyzed. The results show that the maximum principal stress of single hydraulic prop support is $33.3 \%$ higher than that of anchor cable support, and the stress concentration effect of single hydraulic prop support is more obvious, and its vertical stress distribution is poor. The stability of roadway is further improved by using anchor support instead of single hydraulic prop support. The numerical simulation results of roadway displacement show that the displacement of roof, floor, and two sides of roadway is reduced by more than half. The displacement of floor heave is reduced by $68.75 \%$, and the supporting effect is remarkable.

(2) Combined with the results of numerical simulation and the actual situation of 27304 working face in Wanglou coal mine, the specific scheme of grouting anchor cable instead of single hydraulic prop for advance support is designed, and the roof separation instrument and borehole peeper are used to test the support effect. The monitoring results show that compared with the single hydraulic prop support method, the bolt pressure is moderate in grouting anchor support, which indicates that the bolt plays a good supporting role; the displacement of each part of the roadway is small, the roof separation is small, and the integrity is good, and the fracture zone has no effect on the stability of the roadway. The numerical simulation results are in good agreement with the engineering practice. After the anchor cable is used in the advance support section of 27304 working face in Wanglou coal mine, the roadway can meet the requirements of safe and efficient mining.

\section{Data Availability}

The data used to support the findings of this study are available from the corresponding author upon request. 


\section{Conflicts of Interest}

The authors declare that they have no conflicts of interest.

\section{Acknowledgments}

This study was supported by the Shandong Provincial Natural Science Foundation of China (ZR2018MEE001), National Natural Science Foundation of China (no. 51974174), Qingdao Source Innovation Plan (18-2-2-68-jch), and Scientific Research Projects of Colleges and Universities in Shandong Province (J18K2010).

\section{References}

[1] H. Xie, F. Gao, and Y. Jun, "Research and exploration of deep rock mass mechanics," Chinese Journal of Rock Mechanics and Engineering, vol. 34, no. 11, pp. 2161-2178, 2015.

[2] L.-H. Sun, B.-S. Yang, C.-D. Sun, X. Li, and C.-W. Wang, "Experimental research on mechanism and controlling of floor heave in deep soft rock roadway," Journal of Mining \& Safety Engineering, vol. 34, no. 2, pp. 235-252, 2017.

[3] M.-C. He, H. Xie, S.-P. Peng, and Y.-D. Jiang, "Study on rock mechanics of deep mining," Journal of Rock Mechanics and Engineering, vol. 16, pp. 2803-2813, 2005.

[4] H.-W. Zhou, H. Xie, and J.-P. Zuo, "Research progress of rock mechanical behavior under deep high geostress," Progress in Mechanics, vol. 35, no. 1, pp. 91-95, 2005.

[5] W.-B. Zhao, N. Yan, and Z.-X. Cai, "Discussion on present status of mining technology in China's metal mines and its development trend," Nonferrous Metal Design, vol. 38, no. 3, pp. 1-5, 2011.

[6] Z.-J. Chen, "Mechanical problems of long term stability of underground roadway," Chinese Journal of Rock Mechanics and Engineering, vol. 34, no. 1, pp. 1-19, 2011.

[7] T. Li, Stability Analysis and Control of Surrounding Rock in Deep Filling Stope of Large Gold Mine, Beijing University of Science and Technology, Beijing, China, 2019.

[8] X.-X. Chen and J.-P. Wu, "Study on the mechanism and control technology of large deformation of roadway surrounding rock in the fault fracture zone," Journal of Mining o Safety Engineering, vol. 35, no. 5, pp. 885-892, 2018.

[9] J.-P. Zuo, J.-H. Wen, S.-G. Hu, and S.-K. Zhao, “Theoretical model and simulation study of uniform strength beam support in deep coal mine roadway," Journal of China Coal Society, vol. 43, no. supp. 1, pp. 1-10, 2018.

[10] H.-P. Kang, "Support technologies for deep and complex roadways in underground coal mines: a review," International Journal of Coal Science \& Technology, vol. 3, no. 3, 2014.

[11] H.-P. Kang, "Sixty years development and prospects of rock bolting technology for underground coal mine roadways in China," Journal of China University of Mining \&Technology, vol. 45, no. 6, pp. 1071-1081, 2016.

[12] B.-S. Du, "Multi dimension active control technology in large cross section seam gateway in kilometer deep mine shaft," Coal Science and Technology, vol. 38, no. 11, pp. 32-36, 2010.

[13] J.-Y. Wang, S.-W. Ge, and L. Liang, "Application of high prestressed complex active support system to mining gateway," Coal Science and Technology, vol. 38, no. 1, pp. 9-13, 2010.

[14] Q.-B. Zhao and N.-J. Ma, "Research on design method based on complementary principle of bolt anchor cable support in coal roadway with weak and broken surrounding rock," in
Proceedings of 2007 Annual Meeting of Mining Committee of China Coal Society, Datong City, China, 2007.

[15] B. Du, S.-R. Xie, F.-L. He, S.-B. Zhang, Q.-K. Li, and X.-S. Zhu, "Study on complex active support of seam gateway with thick carbonaceous mudstone roof," Coal Science and Technology, vol. 37, no. 2, pp. 13-16, 2009.

[16] Q.-L. Yao, X.-H. Wang, Z. Xia, L.-H. Li, L. Zhu, and X.-H. Li, "Key technology and application of active forepoling for longwall coal mining in coal mine," Journal of Mining \& Safety Engineering, vol. 37, no. 2, pp. 289-297, 2020.

[17] Y. F. Zheng and T. N. Wang, "Experiment study on accessories matching of anchor bolt support system in coal mine-A case study," Advanced Materials Research, vol. 997, pp. 546549, 2014.

[18] C. Cao, N. Jan, T. Ren, and A. Naj, "A study of rock bolting failure modes," International Journal of Mining Science and Technology, vol. 23, no. 1, 2013.

[19] Y. Wu, H. Kang, J. Wu, and F. Gao, "Deformation and support of roadways subjected to abnormal stresses," Procedia Engineering, vol. 26, pp. 665-674, 2011.

[20] S.-H. He, D.-H. Wang, X.-B. Liu, and J.-w. Zhang, “Assessment of the arching effect and the role of rock bolting for underground excavations in rock masses-a new numerical approach," Arabian Journal of Geosciences, vol. 13, no. 13, pp. 262-271, 2020. 